\title{
Encouraging exception reports at an NHS foundation trust
}

\author{
Authors: Santhosh Prasad Jayanti ${ }^{\mathrm{A}}$ and Nishita Padmanabahan ${ }^{\mathrm{B}}$
}

\section{Introduction}

Exception reporting was introduced to allow trainees to flag up work that has varied from their agreed work schedule or did not meet their educational curriculum needs. ${ }^{1-4}$ At our foundation trust (FT), we saw that there were very few exception reports being made throughout the year despite many trainees either staying beyond scheduled hours or missing educational opportunities due to service pressures. We aimed to increase exception reporting by trainees by $20 \%$ at our FT by 1 October 2019 .

\section{Materials and methods}

Junior doctors have an induction in two separate groups: one held for foundation year 1 (FY1) trainees and another held at a different time for all other trainees. We set about joining the induction programme for the trainees starting in the year 2019 to educate them about exception reporting and to encourage them to do so. We were able attend the programme for FY1 trainees but were prevented from doing the same for more senior trainees due to our service commitments, though they received the same from the guardian of safe working, without the voice of a fellow junior doctor. This ended up creating a divide in the form of an intervention and non-intervention group.

During the induction programme, we introduced the concept of exception reporting with the help of the guardian of safe working and its importance. We also engaged juniors regularly in informal settings to encourage exception reporting.

The success of interventions was measured by collating data from Guardian of Safe Working monthly exception report updates.

\section{Results and discussion}

Analysis of data showed for the same period, ie August and September: FY1 trainees exception reported 45 times in 2019, compared with four times in 2018 , demonstrating a tenfold increase, whereas more senior trainees exception reported 25 times in 2019, compared with one time in 2018. The data for senior trainees is to be considered carefully, as this group also included the authors, who were more likely to exception report than others. If we consider the senior trainees' results without our figures included, it would be nine times in 2019, compared with one time in 2018 though still impressive it is not as astonishing.

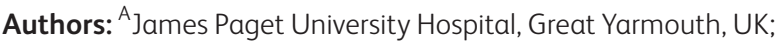
${ }^{B}$ Scunthorpe and Goole Hospital, Scunthorpe, UK

\section{Conclusions}

Exception reporting is an essential tool for both the NHS and trainees in highlighting service pressures as well as where educational objectives aren't met and are likely to lead to better long-term satisfaction with training when issues are highlighted and corrected. Our analysis showed that trainees are more likely to exception report if they are given the knowledge about exception reporting without the assumption that they already know something about it. Uptake is increased when other junior doctors champion exception reporting by leading by example.

\section{Conflicts of interest}

None declared.

\section{References}

1 Royal College of Physicians. Guidance on exception reporting. RCP: London, 2017. www.rcplondon.ac.uk/projects/outputs/exceptionreporting [Accessed 31 October 2019].

2 General Medical Council. Exception reporting two years on. GMC, 2018. www.gmc-uk.org/education/how-we-quality-assure/sharinggood-practice/exception-reporting-two-years-on [Accessed 31 October 2019].

3 NHS Employers. Guidance on rostering and exception reporting. NHS. www.nhsemployers.org/pay-pensions-and-reward/medicalstaff/doctors-and-dentists-in-training/rostering-and-exceptionreporting [Accessed 31 October 2019].

4 British Medical Association. Exception reporting - guidance for junior doctors in England. BMA. www.bma.org.uk/advice/ employment/contracts/junior-doctor-contract/exception-reporting [Accessed 31 October 2019]. 